\title{
Research on modular design of diesel key parts and data management technology
}

\author{
Jibin Hao ${ }^{1, a, *}$, Zhaohua Chen ${ }^{1, b}$, Qiangbo $\mathrm{Xu}^{2, \mathrm{c}}$, Jing Cao ${ }^{3, \mathrm{~d}}$ and Xi Chen ${ }^{4, \mathrm{e}}$ \\ ${ }^{1}$ Department of Information and Digital Center, China North Engine Research Institute, Yong Jin \\ Street, Tianjin, China \\ ${ }^{2}$ Department of Information and Digital Center, China North Engine Research Institute, Yong Jin \\ Street, Tianjin, China \\ ${ }^{3}$ Department of Information and Digital Center, China North Engine Research Institute, Yong Jin \\ Street, Tianjin, China \\ ${ }^{4}$ Department of Information and Digital Center, China North Engine Research Institute, Yong Jin \\ Street, Tianjin, China \\ ${ }^{5}$ Department of Information and Digital Center, China North Engine Research Institute, Yong Jin \\ Street, Tianjin, China \\ a hassar824@126.com, ${ }^{b} 464859729 @ q q . c o m,{ }^{c}$ qb_xu@126.com email, ${ }^{d}$ 546861611@126.com, \\ eqb_xu@126.com, f chx_chenxi@126.com \\ *corresponding author Zhaohua Chen
}

Keywords: Diesel Modularize Design, Module Partition, Sach-Merkleisten, Data Management

Abstract. The paper designs and researches the modular design method of diesel crankshaft based on the research status of the Sach-Merkleisten management technology through analyzing the modular design. On the basis of the crankshaft product and geometry analysis, the crankshaft module division and module creation are carried out and the crankshaft Sach-Merkleisten is created. Furthermore, the paper introduces the classification management of the crankshaft module and the design of parameter management according to the crankshaft modular design process, designs and develops the modular data management system combines with parameterized design tools to verify the data integration, which completes crankshaft module parameters' transfer and storage.

\section{Introduction}

At present, the diesel digital research focus on the construction of the design environment platform, standardizes the process of diesel engine design, refines the evaluation criteria, establishes the diesel components and system whole design process, which is a solid foundation for the establishment of a scientific and advanced diesel digital research and development system. The digital, integrated and parallel modular design technology becomes the key technology for enterprises to occupy a favorable position in the market competition. The research on the theory, method and technology of modular design makes the enterprise to establish the product rapid design and manufacture method, which plays an important role in improving the market competitiveness of 
enterprises. The paper aims to research the application of modular design technology in the design of diesel key parts to develop the rapid design of the diesel key parts, and achieve the purpose of fast modular design and data reuse.

\section{Machine Production Modularize Design Method Research}

The modularize design method has been widely used in different countries. Currently, there is not an authoritative modularize design definition. The basic understanding of the modularize design concept is: on the basis of the functional analysis for productions in a certain range of different functions or the same features with different performance and different specifications, a series of function and structure modules could be carved out, which makes these modules universal and features the standard module interface.[1] User requirements could construct different products through module selection and combination to meet the different requirements of the market design method.[2]

The production modularize design process is based on the analysis of previous production (Bottom-up).[3] Thus, at the beginning of the design process, besides to complete some corresponding basic works such as building coding system 、 component titles analysis v component $\mathrm{ABC}$ analysis and classification of components, it is considered that the following works should be done, as shown in Figure 1.[4] The production modularize design process is as follows:

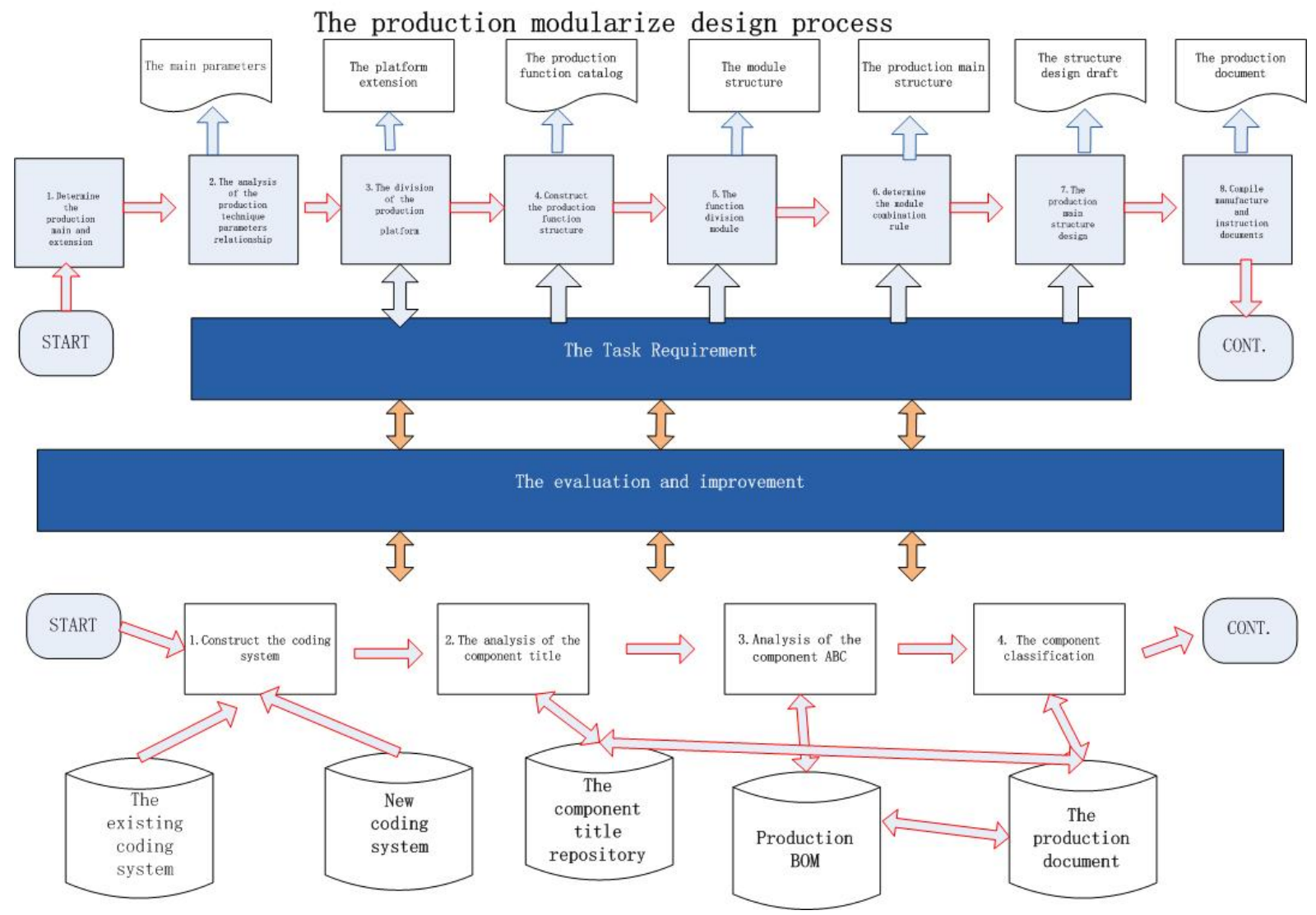

Figure 1 Production modularize design process.

The partition of the assembly layer and component layer in the modularize method is relative, which is different from the product component layer based on the physical structure. The aim of the modularization component layer is to enhance the importance of the component, reduce the amount 
of components and the corporation costs. [5] The design method of the component layer is as follows:

1. Determine the component's important technique parameter extension

According to the component function 、 capability requirement and environment vechnique development, manufacture ability to determine the component important technique parameter extension.

2. Determine the similar type and main parameters

According to the distributing characteristic of the component technique parameter, the component could be divided into two categories, geometry similar component series and semisimilar series. The main parameter of the series component plays the dominant role in different parameters. The relationship between the same category components and matching components should be fully considered when the main parameter is determined. Analyzing the component geometry model could find the similar component class. Through the function and constraint analysis, a representative component geometry model could be proposed. Therefore, the model could meet the function and constraint requirement of the component, which is the graphic foundation of the variant design.[6]

\section{Prototype design}

The prototype design is the most important part in the modularize design process.[7] The midrange component series is chosen to be the prototype in order to expand component series upwards or adown. The size in the prototype should adopt the priority number in the priority number series as much as possible.

4. Determine parameters and size class ratio

The parameter and size class ratio should choose priority numbers. According to the characteristic of the component, it could choose different size ratio combinations. Then the combination of feasible parameters will be filled in the Sach-Merkleisten, then build the corresponding component model and construct its document.[8]

5. Calculate and adjust export component dimension

According to the dimension, parameter and relative ratio of the prototype, the parameter and dimension of the export component could be figured out through calculation and graphic method. When the user's specific requirement and crafts condition are considered, the size and parameters of various specifications could be determined eventually through analyzing and optimizing the result obtained by the theoretical calculation.[9]

\section{Diesel Crankshaft Modularize Design Requirement Analysis}

\subsection{Crankshaft Component Function Analysis}

The figure 2 is the interface analysis of the crankshaft component ontology, the part in the black dotted frame is the main function part of the crankshaft. Base on the above function analysis of the crankshaft, it is known that the important part of drive is the single-throw part, the synthesis of multiple single-throw could complete the coherent rotation motion output.

The absorber segment and flywheel segment are the most important exterior interface segments that assemble corresponding component to help complete crankshaft segment's work. From the function's perspective, the crankshaft could be divided into these three parts. 


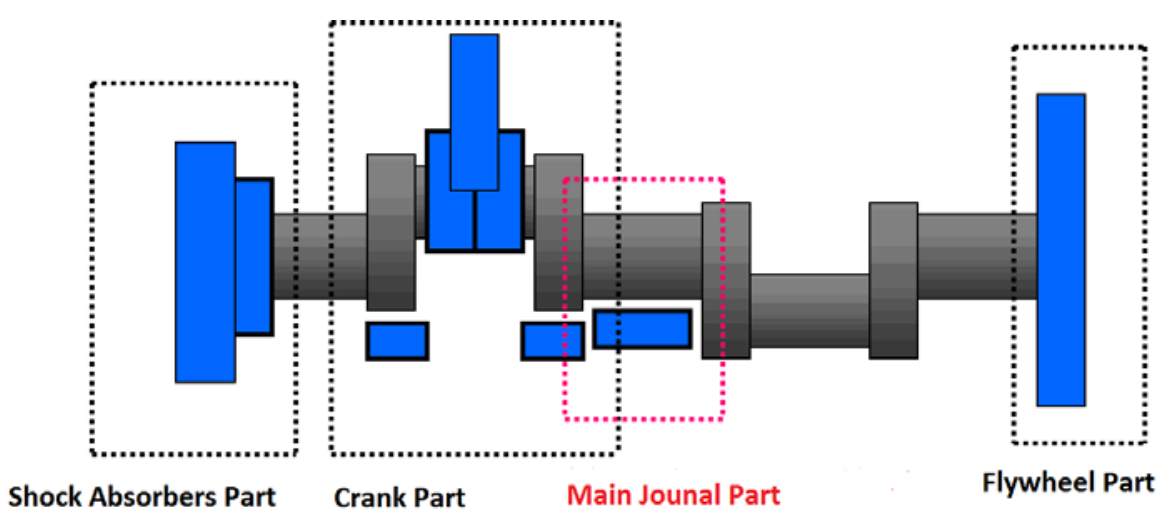

Figure 2 Crankshaft interface analysis.

\subsection{Crankshaft Component Geometry Shape Analysis}

According to the diesel characteristic and designers' experience, the crankshaft could be divided into three parts: front-end, crank and back end, as shown in Figure 3.



Figure 3 Diesel module partition.

1. The front end is also called the free end, mainly used to install the timing gear, belt wheel, starting claw and so on;

2. The crank can be divided into three parts: the main shaft, connecting rod and crank. The main shaft neck is used to support the bearing. The connecting rod journal to install the connecting rod big end, also known as the crank pin. The crank is mainly used for connecting the main shaft neck and the connecting rod journal. The crankshaft has an oil passage that runs through the spindle neck, the crank and the connecting rod journal. Some journals have a balance device to balance the centrifugal force caused by the rotation of the connecting rod and crank. The Figure 4 describes the design process that four shapes are commonly used by designers. According to the output power and force of diesel engine crankshaft, the crank that meets the demand from the four types of crank is selected. Then the variant design is carried out according to its Sach-Merkleisten, so that the crank can be quickly and accurately obtained to meet the demand.

3. The back end includes the flywheel flange, oil retaining flange and oil return thread and so on. The flywheel is mounted on the combined disk, and the power is output. 
The figure 4 shows a schematic diagram of the diesel engine crankshaft modular design.

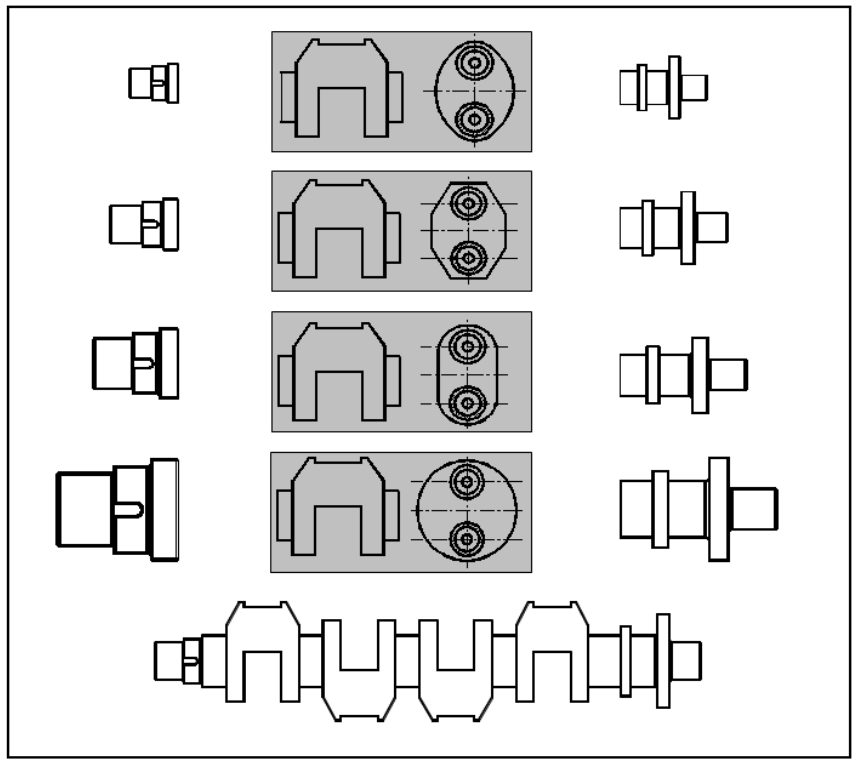

Figure 4 Diesel engine crankshaft modular design schematic diagram.

\section{Crankshaft Modularize Project and Data Manage Design Base on Sach-Merkleisten}

\subsection{Crankshaft Model Partition}

The crankshaft model partition has two parts: overall entity module partition and overall project module partition.

The crankshaft is divided into the free part, single-throw part and output part these three entity modules by the overall entity module. The free part and output part's function structure are simple.

The overall project module includes four parts: overall layout project, overall dimension project, interface project and balance control module. The figure 5 has shown the relationship of four modules.



Figure 5 Crank overall scheme and relationship. 
The internal parameters of the module are controlled and managed by three physical modules. The overall module is controlled by the corresponding module interface parameters to complete the balance of tasks and the overall size of the coordination.

The following example makes a simple introduction to the single crank section module. The diversity of the crankshaft is mainly reflected in the diversity of its crank. The single crank module is composed of two sections of the main shaft neck, the crank pin and the crank arm.

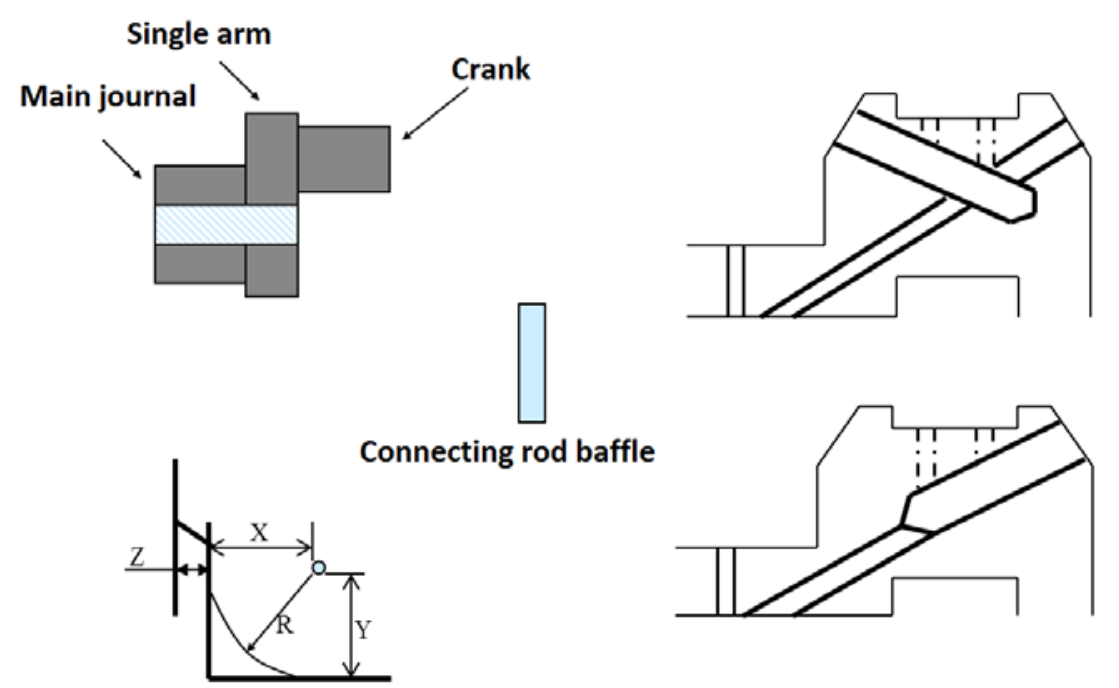

Figure 6 Single crank module decomposition.

The single crank module decomposition is shown as Figure 6, which has been divided into two entity modules: arm turn and connecting rod baffle two entity modules.

\subsection{Crankshaft Parameter Data Management Design Based on Sach-Merkleisten}

\subsubsection{Main Parameters Analysis of Crankshaft Modular Design}

The main dimension of the crank includes: crank radius (A), connecting rod journal (B), shaft neck (C) and crank arm thickness (D), crank pin length (E), shaft neck half length (F) and curved turn length $(\mathrm{H})$. Among them, the crank radius $\mathrm{A}=\mathrm{s} / 2$ ( $\mathrm{s}$ is diesel engine's piston stroke); $\mathrm{H}=\mathrm{D}+\mathrm{E}+2 \mathrm{~F}=\mathrm{L} 0$ (where $\mathrm{L} 0$ is the diesel cylinder center distance).

Through the parameter analysis, the figure 7 shows only five parameters of the diesel engine crank need to be changed, and the rest of the size can be calculated according to these five dimensions, or it is fixed.[10] If this model is combined with the Sach-Merkleisten, a complete and supporting variant designing diesel is formed. 




Figure 7 Parameter analysis of the diesel crank module.

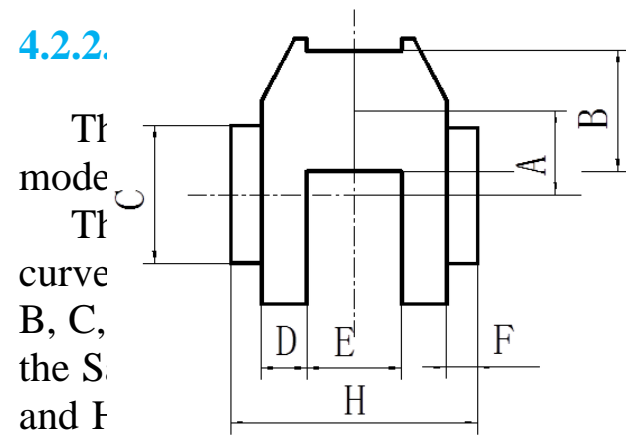

\begin{tabular}{|c|c|c|c|c|c|c|c|}
\hline ID & H & c & $2 \mathrm{~A}$ & B & $E$ & $\mathbf{F}$ & \\
\hline 00001 & & ? & & & & & 50002 \\
\hline 00002 & $\cdots$ & & . & , & & ... & 40005 \\
\hline 00003 & & & - & ; & & & 30002 \\
\hline 00004 & & & & $\therefore ;$ & $\cdots$ & & 20001 \\
\hline
\end{tabular}

mode

differ

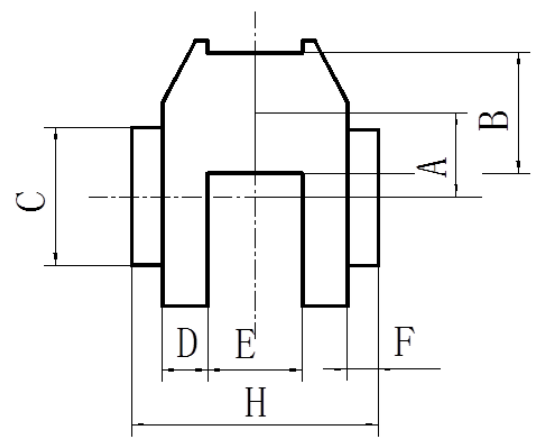

\begin{tabular}{|l|c|c|c|c|c|c|c|}
\hline ID & H & C & 2A & B & E & F & \\
\hline 00001 & & & & & & & 50002 \\
\hline 00002 & $\cdots$ & & & & & & 40005 \\
\hline 00003 & & & - & & & & 30002 \\
\hline 00004 & & & & & & & 20001 \\
\hline & & & & & &
\end{tabular}

Figure 8 Main model of the diesel crank.

The figure 9 shows the diesel engine crank Sach-Merkleisten, the last record of the SachMerkleisten is the crank ID number of the shape element, it points to the next level of the crank Sach-Merkleisten through the pointer. According to the crank ID number, the specific size of the crank could be got through the Sach-Merkleisten. 


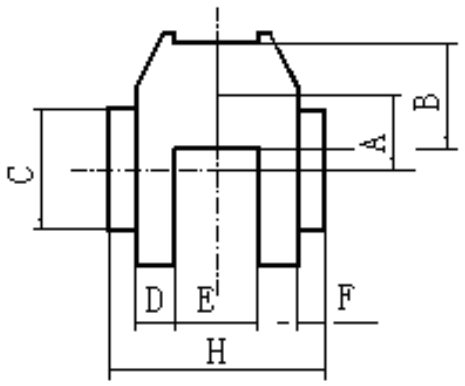

\begin{tabular}{|l|l|l|l|l|l|l|l|}
\hline ID & H & C & 2A & B & E & F & \\
\hline 00001 & & & & & & & \\
\hline 00002 & & & & & & & \\
\hline 00003 & & & & & & & \\
\hline 00004 & & & & & & & \\
\hline & & & & & & & \\
\hline
\end{tabular}

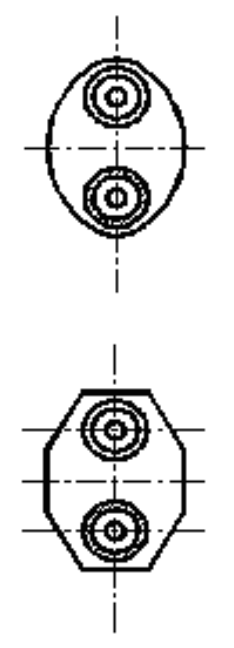

\begin{tabular}{|c|c|c|c|c|c|}
\hline ID & $\boldsymbol{A}_{4}$ & $A_{z}$ & $\cdot A_{2}$ & $A_{1}$ & $A_{s}$ \\
\hline 20001 & & & & & \\
\hline 20002 & & 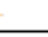 & & & \\
\hline 20003 & & & & & \\
\hline 20004 & & & & & \\
\hline
\end{tabular}
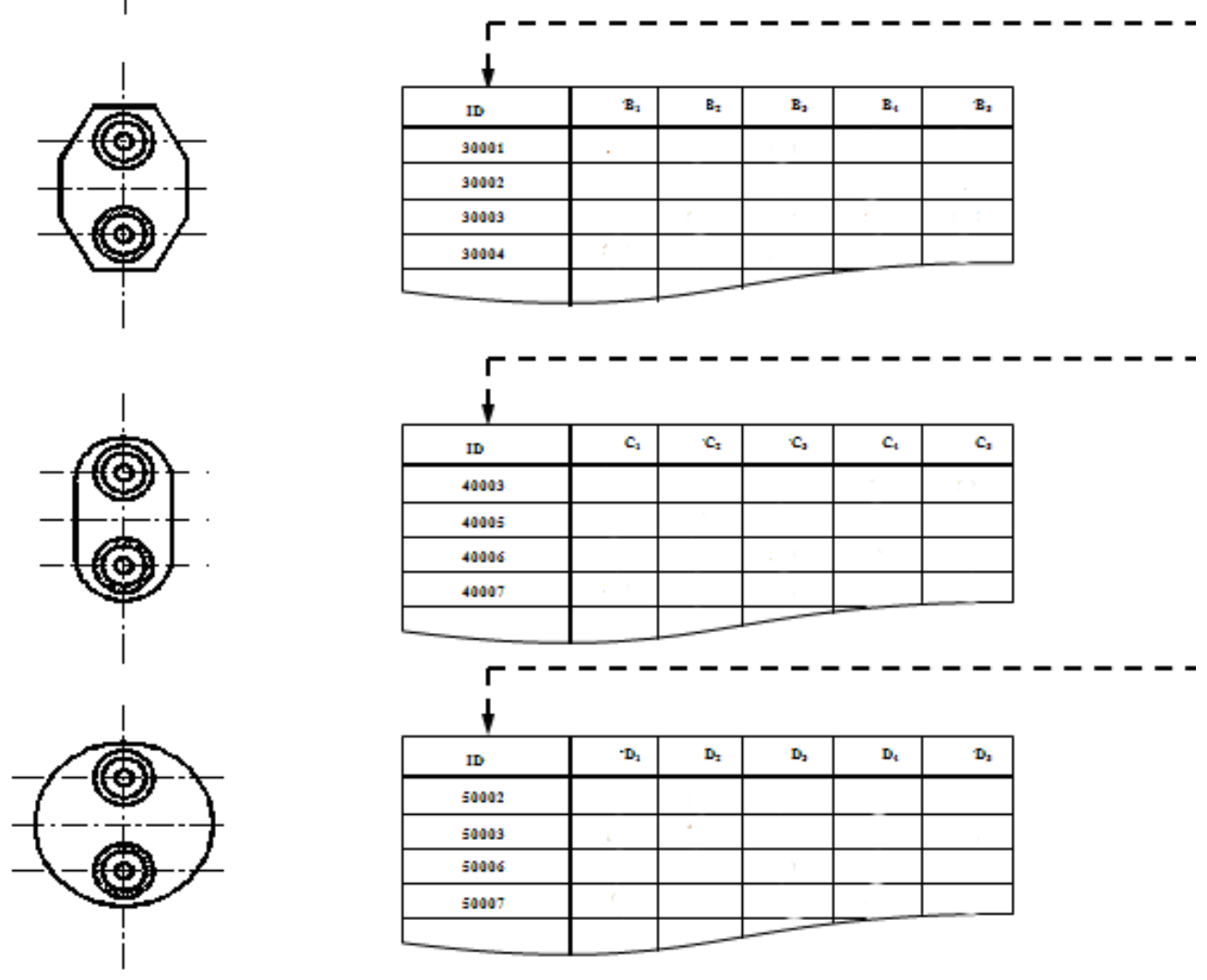

Figure 9 Diesel crank Sach-Merkleisten.

\section{Module parameter management and management system}

\subsection{Crank module classification and parameter Sach-Merkleisten design}

Through the module division of the diesel component, the corresponding data information is divided into modules and layers according to the component module division method, and construct the Sach-Merkleisten for each module.[11] Through the construction of the diesel module classification structure tree, unique classification code could be formed to managing the module classification structure and establish the component parameter Sach-Merkleisten. [12] 


\subsection{Modular management system}

The system is mainly composed of five modules: system configuration module, parameter pool module, Sach-Merkleisten pool management module, Sach-Merkleisten modeling module and Sach-Merkleisten data maintenance module. Among them, the Sach-Merkleisten pool management module and Sach-Merkleisten modeling module are the core module of the system, which is used to manage the component module parameters and store the component module parameter instance data.[13] The system function structure diagram is shown as the figure 10.



Figure 10 System function module and system structure.

\section{Conclusions}

The paper is based on the system research modular design theory and Sach-Merkleisten based management techniques, through the analysis of modular and diesel crankshaft design, the crankshaft modular design project and Sach-Merkleisten have been constructed, the module data management system has been developed. The main conclusions of this paper are as follows:

1. Reviews the design principle of the diesel component design method based on the modular design method, formats the general process of the component modular design, concretes steps for the detail process of modular design and provides the technical support for the crankshaft module partition and project design.

2. Researches the crankshaft product and its geometric characteristics, analyzes the crankshaft modular design problems, puts forward the specific method and procedure of the modular design of the crankshaft and analyzes the Sach-Merkleisten.

3. Develops the modular data management system, achieves the module of the classification management, parameter management, parameter instance data management.

\section{REFERENCES}

[1] KIM G J, BEKEY G. Design for assembly by reverse engineering [A]. Artif -icial Intelligence in Designp9 4 [C].Dordrecht : Kluwer Academic Publishers ,1994 : 717734.

[2] MARTINO T D , FALCIDIENO B , HAßINGER S.Design and engineering process integration through a mu 
ltiple view intermediate modeller in a distributed object-oriented system environment [J]. Computer Aided Design, 1995,30(6): 437452.

[3] GORTI S R , GUPTA A , KIM G J , etal . An object-oriented representation for product and design processes [J] . Computer Aided Design,1998,30 (7) : 489501.

[4] JIAO Jian xin , TSENG M M , DUFFY V G, etal. Product family modeling for mass customization [J]. Com puters Industry Engineering, 1998 ,35 (3/4):495 498.

[5] ALEXANDER F, GERHARD F , DIETMAR J .Conceptual modeling for configuration of mass-customizab le products [J] . Artificial Intelligence in Engineering ,2001,15 (2):165 176.

[6] Schöttner J. The missing link[J]. CAD World, 2000(3):95 96.

[7] Schöttner J. PDM and E-business[J]. Industrielle IT, 2000(4):16-18.

[8] K.M.M.Holtta, K.N.Otto. Incorporating design effort complexity measures in product architectural design and assessment[J]. Design Studies, 2005, 26 (5): 464-485.

[9] F.Alizon, S.B.Shooter, T.W.Simpson. Improving an existing product family based on commonality/divers ity, modularity, and cost[J]. Design Studies, 2007, 28 (4): 387-409.

[10] Dobrescu.G, Reich.Y. Progressive sharing of modules among product variants[J]. Computer-Aided Desig n, 2003, 35(9):791-806.

[11] H.E.Tseng. Modular design to support green life-cycle engineering[J]. Expert Systems with Applications, 2008, 34(4): 2524-2537.

[12] Kusiak A, Huang C. Developments of modular products[J].IEEE Transactions on Components Packaging and Manufacturing Technology - Part A , 1996, 19(4): 523-538.

[13] Hillstrom, Fredrik, Applying axiomatic design to interface analysis in modular product development, A merican Society of Mechanical Engineers, Design Engineering Division(Publication)DE v69-2 Sep 11-14, 199 4, ASME p363-371. 